\title{
Analysis of Human Breath by Millimeter-Wave/Terahertz Spectroscopy
}

\author{
Nick Rothbart $1,2, *$, Olaf Holz ${ }^{3,4}$, Rembert Koczulla ${ }^{4,5,6,7}$, Klaus Schmalz 8 \\ and Heinz-Wilhelm Hübers ${ }^{1,2}$ \\ 1 Institute of Optical Sensor Systems, German Aerospace Center (DLR), 12489 Berlin, Germany; \\ heinz-wilhelm.huebers@dlr.de \\ 2 Department of Physics, Humboldt-Universität zu Berlin, 12489 Berlin, Germany \\ 3 Fraunhofer Institute for Toxicology and Experimental Medicine ITEM, Biomedical Research in Endstage and \\ Obstructive Lung Disease Hannover (BREATH), 30625 Hannover, Germany; olaf.holz@item.fraunhofer.de \\ 4 The German Center for Lung Research (DZL), 35043 Marburg/35392 Giessen, Germany; \\ rkoczulla@schoen-klinik.de \\ 5 Department of Pulmonology, Institute for Internal Medicine, Philipps-University of Marburg, \\ 35043 Marburg, Germany \\ 6 Schön Klinik Berchtesgadener Land, Department for Pulmonology, Teaching Hospital of the Philipps-University, \\ 35043 Marburg, Germany \\ 7 Teaching Department of the Paracelsus University Salzburg, 5020 Salzburg, Austria \\ 8 IHP_Leibniz-Institut für innovative Mikroelektronik, 15236 Frankfurt (Oder), Germany; \\ schmalz@ihp-microelectronics.com \\ * Correspondence: nick.rothbart@dlr.de
}

Received: 8 May 2019; Accepted: 13 June 2019; Published: 17 June 2019

check for updates

\begin{abstract}
Breath gas analysis is a promising tool for medical research and diagnosis. A particularly powerful technological approach is millimeter-wave/terahertz $(\mathrm{mmW} / \mathrm{THz})$ spectroscopy, because it is a very sensitive and highly selective technique. In addition, it offers the potential for compact and affordable sensing systems for wide use. In this work, we demonstrate the capability of a mmW/THz spectrometer for breath analysis. Samples from three volunteers and a sample from ambient air were analyzed with respect to 31 different molecular species. High-resolution absorption spectra were measured by scanning two absorption lines from each species. Out of the 31, a total of 21 species were detected. The results demonstrate the potential of $\mathrm{mmW} / \mathrm{THz}$ spectroscopy for breath analysis.
\end{abstract}

Keywords: breath analysis; millimeter-wave; terahertz; spectroscopy; molecular spectroscopy; gas sensing

\section{Introduction}

\subsection{Breath Gas Analysis}

The analysis of exhaled human breath is a very promising tool for medical applications. Since it is completely non-invasive, it has the potential to become a very convenient method for medical diagnoses or screenings. Furthermore, in contrast to a blood test, breath can be sampled fast and as often as required and an on-site measurement is possible. This allows also for the use of real-time studies.

More than 2000 years ago, Hippocrates started medical breath gas analysis when he realized that the aroma of breath can provide clues to diagnoses. Since then, physicians linked the smell of the breath to diseases, for instance the fruity odor of acetone to diabetes [1]. Nowadays, the alcohol breath test is a very prominent and well-established example for breath analysis. The blood alcohol concentration is approximated by the breath alcohol concentration, which is lower by a factor of roughly 
2400 [2]. Compounds are exchanged between blood and breath by diffusion through the pulmonary alveolar membrane. However, the study of human exhaled breath can provide much more information than ethanol or acetone concentrations. Along with the main components nitrogen, oxygen, carbon dioxide, water, and inert gases, thousands of Volatile Organic Compounds (VOCs) were detected so far in human breath with a large variety between people and with concentrations ranging from ppt to ppm [3-5]. Some main VOCs common to all humans are isoprene, acetone, and methanol $[3,6]$. The compounds' origins can be endogenous (from the host), from microorganisms (in lungs, mouth, and gut), or exogenous from the environment [7].

The large amount of information in breath offers a path towards a better understanding of metabolism and medical diagnosis. Reviews give an overview about the large variety of research involved with the analysis of human breath $[7,8]$. One example is the study of acetone concentrations in diabetes patients $[9,10]$. For patients with critical ketoacidotic diabetes, the acetone concentration can increase up to a few $100 \mathrm{ppm}$ compared to around $0.5 \mathrm{ppm}$ for healthy persons [11]. With more than 400 million diabetes patients worldwide, diabetes screening or monitoring has a large economic impact. Other human breath research includes studies on Chronic Obstructive Pulmonary Disease (COPD) or on systemic inflammation [12,13]. A method based on infrared spectroscopy is already successfully in use to plan liver surgery. With this method, the liver status of patients is determined by the exhaled isotopologue ratio of carbon monoxide after administration and metabolism of a ${ }^{13} \mathrm{C}$-labelled methacetin [14]. Breath analysis is also considered as a tool for therapeutic drug monitoring [15]. Due to its capability of fast and long-term sampling, real-time on-site measurements can be performed as well. Accordingly, it was observed that isoprene concentrations increase immediately with physical effort and acetone as well as isoprene levels change during sleep $[4,16]$.

Sampling of the exhaled air is a crucial step in breath analysis. For instance, it has to be taken into account that the first portion of the exhalation is dead space, whereas the later portion contains alveolar air, which contains most of the valuable information [17]. Furthermore, external effects such as the ambient air, food and beverage intake, teeth brushing, smoking, and a number of further factors can influence the measurement and have to be considered $[18,19]$. Various methods for exhaled air sampling and storing, such as polymer/Tedlar bags, were demonstrated. Often, the sampled breath is pre-concentrated either by solid-phase microextraction or by thermal desorption $[7,20,21]$. Thermal desorption tubes filled with Tenax $(\subset$ are widely used and thus a good tool for standard sampling procedures. Standardization of sampling protocols is a major challenge in breath gas analysis and very important to compare different studies [19].

The method most widely used for the analysis of breath gas is gas-chromatography combined with mass-spectroscopy (GC-MS). This technology is very sensitive. However, it is not an option for regular clinical diagnosis because of the high cost of the instrument and very complex and time-consuming handling. Furthermore, light molecules with molecular masses below $35 \mathrm{~g} / \mathrm{mol}$, such as methanol, are challenging or not even possible to detect. Extensive overviews about breath analysis techniques are given elsewhere [11,22].

\subsection{Millimeter-Wave/Terahertz Gas Spectroscopy}

Millimeter-wave $(\mathrm{mmW})$ /terahertz $(\mathrm{THz})$ gas spectroscopy is based on rotational transitions of molecules which are excited by the radiation. Depending on the molecules' structure, the strongest rotational transitions are typically located around $100-500 \mathrm{GHz}$ [23]. For methanol, the strongest transition between 200 and $300 \mathrm{GHz}$ has a line intensity of $8.3 \times 10^{-23} \mathrm{~cm}^{-1} /\left(\right.$ molecule $\left./ \mathrm{cm}^{2}\right)$ resulting in $15 \%$ absorption at a pressure of 10 Pa per 1 meter absorption length [24]. As in infrared vibrational spectroscopy the $\mathrm{mmW} / \mathrm{THz}$ spectra can be used for analytical purposes. A typical spectrometer for high-resolution $\mathrm{mmW} / \mathrm{THz}$ spectroscopy consists of a radiation source, an absorption cell, a detector, and optical elements. The radiation is transmitted through an absorption cell, which is filled with a gas at a particular pressure and impinges on a detector, which generates an output voltage or current. The method is highly specific and selective due to the very high spectral resolution in combination with 
large spectral coverage. For example, a mmW/THz spectrometer with a transmitter and a heterodyne receiver can cover a frequency range of $100 \mathrm{GHz}$ with a spectral resolution of $0.1 \mathrm{MHz}$. This results in $10^{6}$ spectral channels. Common breath gases, such as acetone, methanol, and ethanol, reveal more than 1,000 absorption lines within the $200-300 \mathrm{GHz}$ range [24]. Furthermore, the absorption lines are as narrow as a few $\mathrm{MHz}$ at typical pressures of a few $\mathrm{Pa}$, so there is little spectral overlap between the lines. Correspondingly, the spectra provide unique fingerprints for molecular species and the specificity and selectivity which can be obtained with a $\mathrm{mmW} / \mathrm{THz}$ spectrometer can be considered as absolute [25].

$\mathrm{MmW} / \mathrm{THz}$ gas spectrometers have been realized with different technologies and high sensitivity has been demonstrated [26-33]. Ethanol, methanol, and acetone have been unambiguously detected in human breath down to ppt levels [34-36]. In each of these works, the breath was collected in a Tedlar bag and pre-concentrators based on thermal desorption were used (custom-made [34] and commercial [35,36], respectively).

Due to its unique properties, $\mathrm{mmW} / \mathrm{THz}$ spectroscopy can provide a valuable contribution to breath analysis. High sensitives that can compete with established methods were demonstrated. Furthermore, the specificity and selectivity is excellent such that $\mathrm{mmW} / \mathrm{THz}$ spectroscopy can provide complementary information about molecules that can't be detected by other approaches. Finally, $\mathrm{mmW} / \mathrm{THz}$ spectroscopy systems are relatively simple compared to other techniques, enabling widespread applications in the future.

In this paper, we demonstrate sensitive and selective breath gas analysis of many different molecules by $\mathrm{mmW} / \mathrm{THz}$ gas spectroscopy. The breath of three patients is sampled using a breath sampling device and Tenax@ thermal desorption tubes.

\section{Materials and Methods}

\subsection{Breath Sampling}

Breath specimens were sampled using a setup at the Fraunhofer Institute for Toxicology and Experimental Medicine in Hannover. The sampling device and the sampling procedure were already established in previous studies using gas chromatography-mass spectroscopy for the breath analysis. A detailed description of the device can be found in Reference [37]. The volunteers breathed into an aluminum reservoir tube through a sterilized mouthpiece and a lung function sterile filter. By inhalation through a carbon filter, contamination of the inhaled air by VOCs in the ambient air was reduced. In order to get rid of residual contaminations, each volunteer breathed 3 minutes through the filter before sampling started. Subsequently, the persons continued breathing for 5 minutes while a constant airflow of $500 \mathrm{~mL} / \mathrm{min}$ from the reservoir tube through the Tenax@ thermal desorption pre-concentrator tubes was maintained by pumping. In total, 3 healthy male volunteers (P1, P2, P3) were sampled with P3 being a smoker (1 pack/day). In addition, one tube was loaded with ambient air during sampling of $\mathrm{P} 1$. The samples shall demonstrate the proof of our concept and were selected for practical reasons without claiming any valid representation. All samples were stored in the Tenax@ tubes which were closed by a cap to keep them airtight. The tubes were carried to German Aerospace Center in Berlin, where they were measured on the next day.

\subsection{Gas Spectroscopy Setup}

The scheme of the mmW/THz spectrometer is shown in Figure 1. It is based on a transmitter (TX) and a heterodyne receiver (RX) (both from Virginia Diodes Inc., Charlottesville, VA, USA). TX and $\mathrm{RX}$ are equipped with diagonal horn antennas. They cover a frequency range from 220-330 GHz. The typical output power of the TX is $-2 \mathrm{dBm}$. The RX has a $33 \mathrm{GHz}$ IF bandwidth, a single sideband noise figure of $12 \mathrm{~dB}$ and a typical system conversion gain of $+2 \mathrm{~dB}$. A discussion of the sensitivity of a similar spectrometer can be found in [30]. 


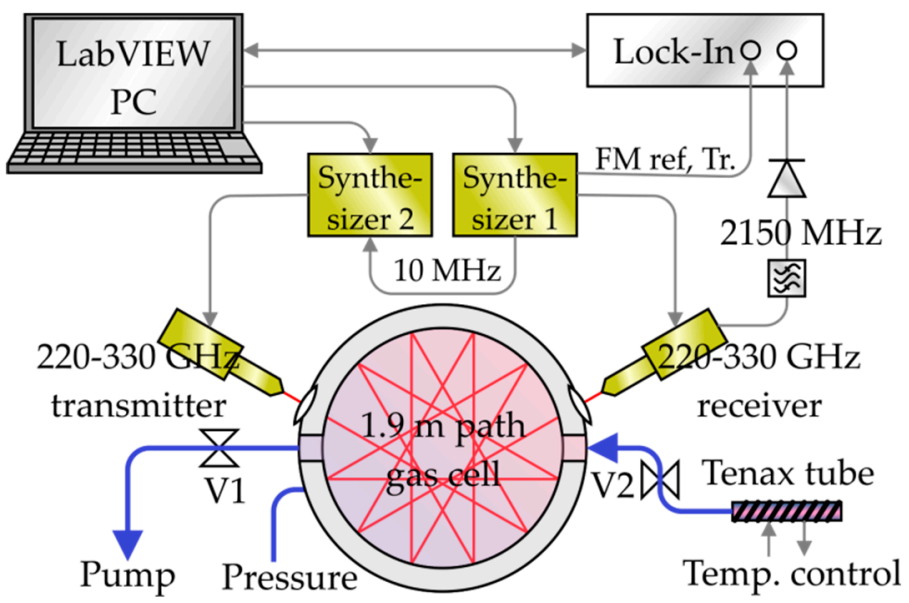

Figure 1. Setup of the $\mathrm{mmW} / \mathrm{THz}$ gas spectrometer for breath analysis. The volunteer's breath is released into the gas cell by heating of the Tenax $(C$ tube. The desorbed gas is analyzed by second harmonic (2f)-spectroscopy in the frequency range from 220 to $330 \mathrm{GHz}$.

The emitted TX frequency and the local oscillator frequency of the RX are controlled by two synthesizers operating between 9 and $14 \mathrm{GHz}$ whose output frequencies are multiplied by a factor of 24. Both are synchronized to a common $10 \mathrm{MHz}$ reference oscillator. A constant intermediate frequency (IF) of $2150 \mathrm{MHz}$ between TX and RX is set. The IF signal at the output of the RX is filtered by a bandpass and rectified by a Schottky diode power detector (Agilent 8472B, Santa Clara, CA, USA). The TX is frequency-modulated with $30 \mathrm{kHz}$ and a $500 \mathrm{kHz}$ amplitude. The amplitude was chosen as a compromise between signal strengths and standing waves, both increasing with higher modulation amplitudes. The standing waves appeared as a result from a Fabry-Pérot resonance between the TX and the RX. A lock-in detector (Zurich Instruments HF2LI, Zurich, Switzerland) detects the second harmonic (2f) content of the IF power, which results in 2nd derivative-like shapes of the signals. This method enhances the sensitivity and reduces standing waves in the spectra. The lock-in amplifier is synchronized to the modulation frequency and trigger signals of synthesizer 1 . The frequencies of the synthesizers and the lock-in amplifier are controlled with a custom-made LabVIEW program. A circular multi-pass gas cell with a total absorption length of $1.9 \mathrm{~m}$ is used. Two high-density polyethylene (HDPE) lenses focus the radiation from the TX into the cell and at the output of the cell into the RX. The gas cell has three vacuum ports for the pump (with valve V1), the pressure sensor, and the inlet. The Tenax@ tube is connected to the absorption cell via a valve (V2). In order to facilitate thermal desorption the tube can be heated by a custom made heater based on a $50 \mathrm{Ohm}$ resistor. The heater consists of an aluminum block where the tube is attached to. A temperature sensor placed close to the Tenax@ tube and a temperature controller (Cryocon 24C, Rancho Santa Fe, CA, USA) allow for a precise control of the tube temperature.

\subsection{Sample Handling and Measurement Procedure}

In this section, the sample handling and measurement procedure is described. It includes the thermal desorption of the samples and inlet of the released gases in the gas cell as well as the measurement of the spectra. Each of the four samples, the ambient air and three volunteers' samples, was handled the same way to allow for a comparison of the data. First of all, each Tenax@ tube was connected to the heater and attached to the gas cell with the breath intake pointing towards the gas cell inlet. The other end was kept closed by the cap. The gas cell and the tube were evacuated to around $0.5-0.7 \mathrm{~Pa}$ (V2 open). The quite high pressure is due to outgassing of the Tenax@ even without heating. Therefore, measurements were taken already at this pressure (run 0). Subsequently, valve V2 (cf. Figure 1) was closed while the pump remained evacuating the cell to a residual pressure of 0.01 to $0.1 \mathrm{~Pa}$. The tube was heated to $250^{\circ} \mathrm{C}$, which took about 7 minutes, and stayed at this temperature 
for another 5 minutes before the released gas was let into the gas cell. This high temperature was chosen because it favors thermal desorption on the one hand. On the other hand, a high temperature might cause decomposition of some compounds, which has to be addressed in future work. With the valves V1 and V2, the pressure in the gas cell was set to $5 \mathrm{~Pa}$. This pressure was chosen as an optimum between large signals and narrow linewidths. At this point, spectra of the breath sample inside the cell were taken (run 1). Individual absorption lines of 31 molecular species were scanned with a $10 \mathrm{MHz}$ range around their center frequency. The species were chosen according to their relevance to breath analysis and the availability of spectral reference data. For each species, two absorption lines were scanned-except for carbon monoxide and hydrogen cyanide, each having only one absorption line in the available frequency range. The measured lines were chosen by their strengths and isolation from other lines. From the 31 species, 21 species were detected by at least one line in at least one sample. The detected species are shown in Table 1 . The species that were not detected are ethylene, nitrogen dioxide, dimethyl ether, methyl chloride, acrylonitrile, propionitrile, sulfur dioxide, propionic acid, toluene, and ethyl benzene. This results from concentrations that are too low and/or from too weak absorption lines. After measuring the spectra, the gas cell was evacuated and filled again with $5 \mathrm{~Pa}$ from the heated Tenax@ tube. With this filling, another measurement was performed in the same way. In total, each line was scanned four times, once before starting of the heating (run 0 ) and three times after the heating (run 1-3). Between the runs, there was a time span of about 20 minutes.

Table 1. Detected molecular species and corresponding scanned absorption lines sorted by the molecular masses $\mathrm{M}$. The lines were chosen by strength and isolation from other known lines. The line positions were taken from [24] $(\mathrm{M}<61)$ and [38] $(\mathrm{M}>61)$. Lines marked with a star $\left(^{*}\right)$ were searched for but not detected in the spectra. Hydrogen cyanide and carbon monoxide have only one line in the spectral range of the spectrometer.

\begin{tabular}{cccccc}
\hline Compound & Molecular Formula & CAS Number & M (g/mol) & \multicolumn{2}{c}{ Line Positions (GHz) } \\
\hline Water & $\mathrm{H}_{2} \mathrm{O}$ & $7732-18-5$ & 18.02 & 325.153 & 321.226 \\
Hydrogen cyanide & $\mathrm{HCN}$ & $74-90-8$ & 27.03 & 265.886 & - \\
Carbon monoxide & $\mathrm{CO}$ & $630-08-0$ & 28.01 & 230.538 & - \\
Nitrogen oxide & $\mathrm{NO}$ & $10102-43-9$ & 30.01 & 250.437 & 257.822 \\
Formaldehyde & $\mathrm{CH}_{2} \mathrm{O}$ & $50-00-0$ & 30.03 & 225.698 & 281.527 \\
Methanol & $\mathrm{CH}_{3} \mathrm{OH}$ & $67-56-1$ & 32.04 & 309.29 & 241.7 \\
Hydrogen sulfide & $\mathrm{H}_{2} \mathrm{~S}$ & $7783-06-4$ & 34.08 & 300.506 & $314.438^{*}$ \\
Acetonitrile & $\mathrm{CH}_{3} \mathrm{CN}$ & $75-05-8$ & 41.05 & 312.634 & 239.119 \\
Methyl isocyanide & $\mathrm{CH}_{3} \mathrm{NC}$ & $593-75-9$ & 41.05 & 301.495 & $301.461 *$ \\
Acetaldehyde & $\mathrm{CH}_{3} \mathrm{CHO}$ & $75-07-0$ & 44.05 & 299.175 & 312.784 \\
Ethanol & $\mathrm{CH}_{3} \mathrm{CH} \mathrm{HH}_{2} \mathrm{OH}$ & $64-17-5$ & 46.07 & 242.35 & 316.502 \\
Vinyl isocyanide & $\mathrm{CH}_{2} \mathrm{CHNC}$ & $14668-82-7$ & 53.06 & 230.875 & $316.175^{*}$ \\
Acrolein & $\mathrm{CH}_{2} \mathrm{CHCHO}$ & $107-02-08$ & 56.06 & 309.454 & 319.636 \\
Acetone & $\mathrm{CH}_{3} \mathrm{COCH} 3$ & $67-64-1$ & 58.08 & 249.805 & 316.224 \\
Carbonyl sulfide & $\mathrm{OCS}_{3}$ & $463-58-1$ & 60.08 & 303.993 & 291.84 \\
Dimethyl sulfide & $\mathrm{CH}_{3} \mathrm{SCH}_{3}$ & $75-18-3$ & 62.13 & 222.003 & $256.269 *$ \\
Isoprene & $\mathrm{CH}_{2} \mathrm{CCH}_{3} \mathrm{CHCH}$ & $78-79-5$ & 68.12 & 236.101 & 247.714 \\
Butyraldehyde & $\mathrm{CH}_{3} \mathrm{CH}_{2} \mathrm{CH}_{2} \mathrm{CHO}$ & $123-72-8$ & 72.11 & 247.481 & $245.465 *$ \\
Methyl nitrate & $\mathrm{CH}_{3} \mathrm{NO}_{3}$ & $598-58-3$ & 77.04 & 236.624 & $243.849 *$ \\
Pyruvic acid & $\mathrm{C}_{3} \mathrm{H}_{4} \mathrm{O}_{3}$ & $127-17-3$ & 88.06 & 239.23 & $235.767 *$ \\
Butyric acid & $\mathrm{CH}_{3} \mathrm{CH}_{2} \mathrm{CH}_{2} \mathrm{COOH}$ & $107-92-6$ & 88.11 & 247.756 & $246.573 *$ \\
\hline
\end{tabular}

\section{Results and Discussion}

Line scans with the largest signal for each species in the smoker's sample P3 are shown in Figure 2. The derivative-like shapes result from the second harmonic (2f) detection, which is described in Reference [39]. The peak-to-peak signals vary by more than three orders of magnitude from $0.3 \mu \mathrm{V}$ for acrolein and methyl isocyanide to $1630 \mu \mathrm{V}$ for water. With the root-mean-square (RMS) noise level of $250 \mathrm{nV}$, this corresponds to signal-to-noise ratios between 1 and 6500. In a reference measurement of 
pure water vapor (line intensity $9.0 \times 10^{-23} \mathrm{~cm}^{-1} /\left(\right.$ molecule $/ \mathrm{cm}^{2}$ ) @ $325.153 \mathrm{GHz}$ [24]) we observed a signal of $1870 \mu \mathrm{V}$. From that, we can estimate the water content in our sample to $88 \%$ and extrapolate the detection limit (SNR = 1) to $130 \mathrm{ppm}$ without pre-concentration. Accordingly, the detection limit for hydrogen cyanide (line intensity $2.9 \times 10^{-20} \mathrm{~cm}^{-1} /\left(\right.$ molecule $\left./ \mathrm{cm}^{2}\right) @ 265.886 \mathrm{GHz}$ [24]) is approximately $400 \mathrm{ppb}$ without pre-concentration. Each line was scanned in a range of $10 \mathrm{MHz}$ around its center frequency with each scan taking 5 seconds at a $50 \mathrm{~ms}$ integration time and $100 \mathrm{~Hz}$ sampling rate. The modulation frequency was set to $30 \mathrm{kHz}$ with a $500 \mathrm{kHz}$ amplitude. For all scans, the phase of the lock-in amplifier was adjusted for maximum signal by post-processing of the data. The baseline was distorted by standing wave patterns with a $5 \mu \mathrm{V}$ amplitude and $67 \mathrm{MHz}$ period corresponding to a $2.2 \mathrm{~m}$ resonator which is the optical distance between TX and RX. The standing wave pattern was eliminated by post-processing of the data.
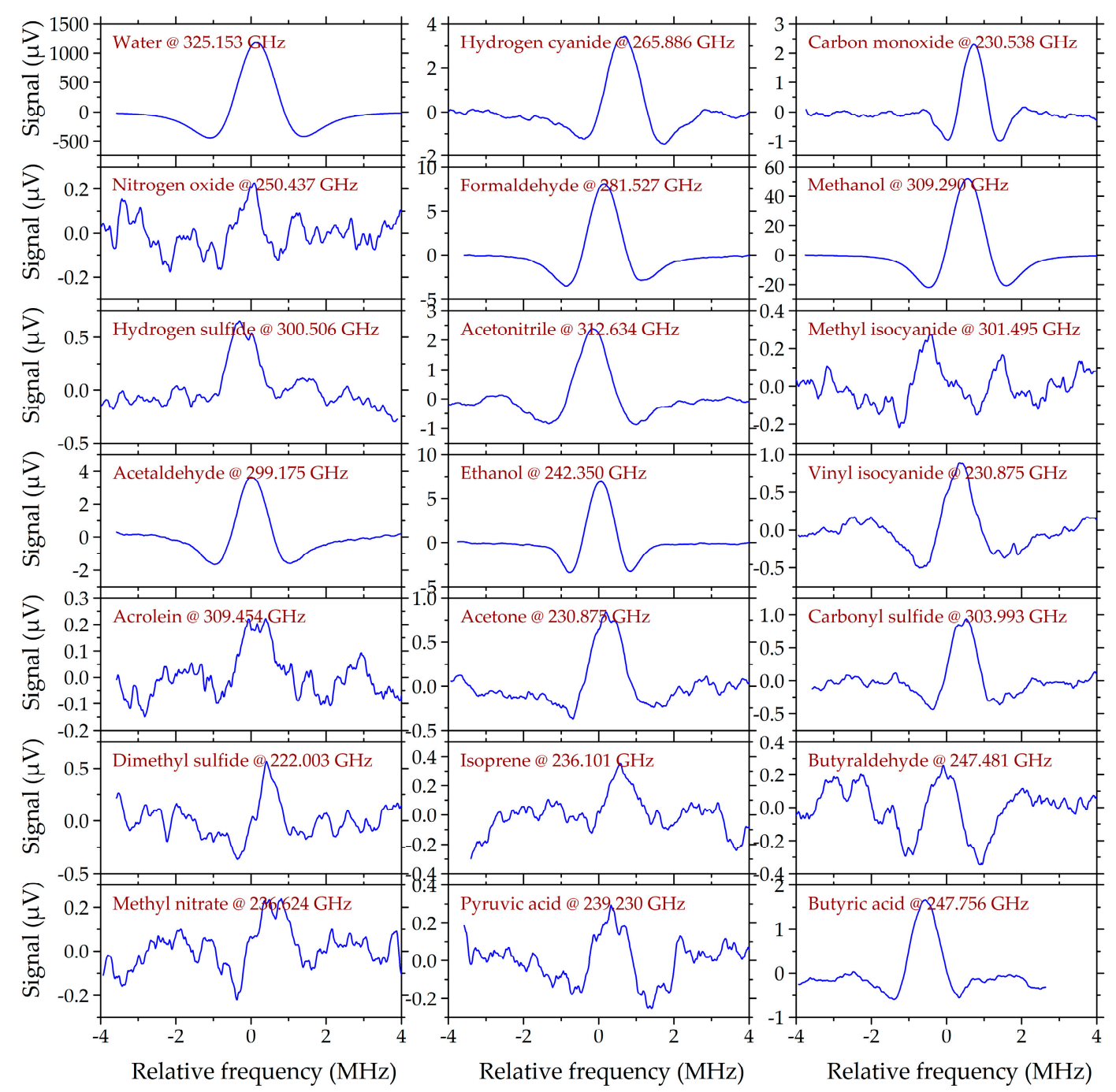

Figure 2. Line scans of the smoker's sample (P3) with the largest signal for each molecular species. The signal-to-noise ratios range from 1 (acrolein, methyl isocyanide) to 6500 (water). The lock-in phase and the baseline of each scan were processed after the measurements.

From all four scans for each species, the scan with the largest peak-to-peak signal was considered for the comparison between the volunteers. Most species revealed the largest signal in run 1 or run 2 after the heating of the tube started, meaning they were released easily, whereas some molecules were released later, as they provided the largest signal in run 3. But this signal was only slightly larger than that of run 2. Some examples of the P3 sample are shown in Figure 3. It should be noted that ethanol 
provided a large signal also in run 0 before we even started heating the tube. Therefore, the signal is not directly comparable with runs 1-3 measured at a pressure of $5 \mathrm{~Pa}$. All other species were not detected or detected with much weaker signal in the scan before heating (run 0 ) than during heating of the tube (runs 1-3).

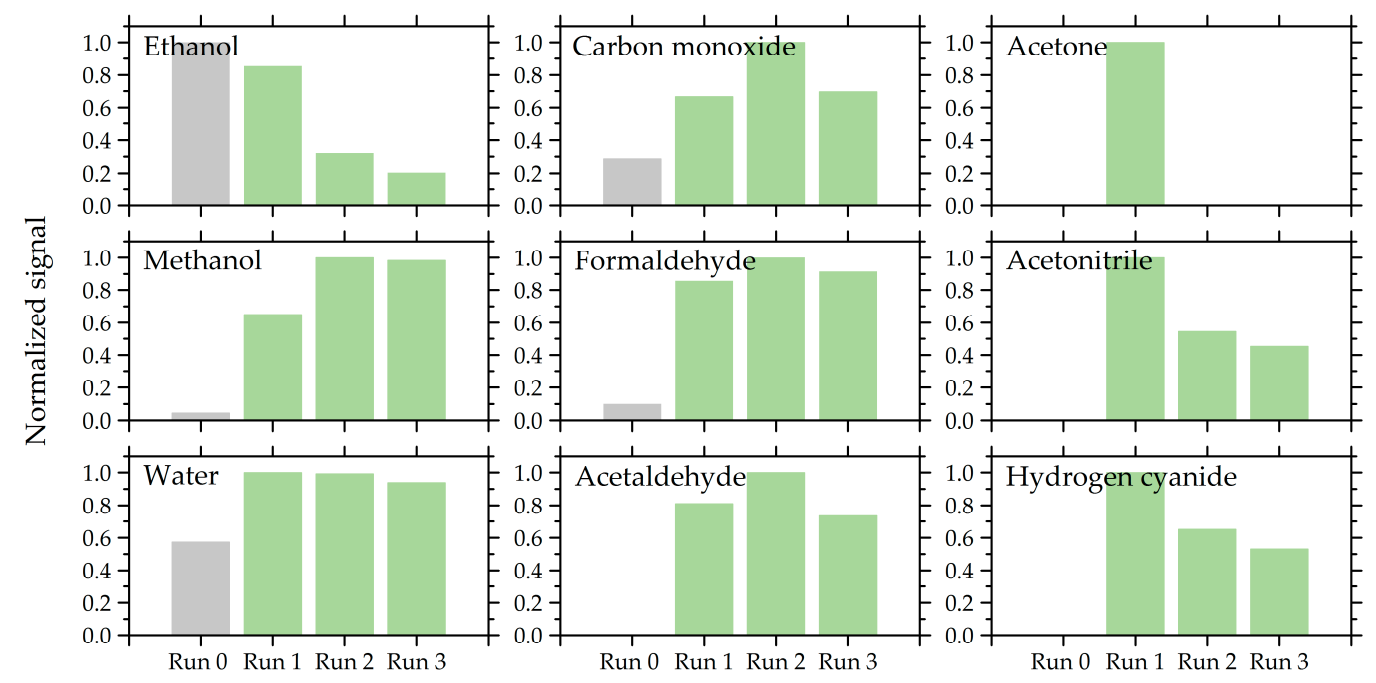

Figure 3. Variation of the amplitude between the subsequent scans of the P3 sample. Most species revealed the strongest signal in the first or second scan after heating (run 1 or run 2).

In Figure 4, the maximum peak-to-peak signals measured for each species are shown for the ambient air and the three volunteers' samples. Molecules marked with a star were detected by one line only. This might be a consequence of the second line scanned being too weak or of the fact that there is only one absorption line in the available frequency range (see Table 1). However, single line detection can in principle result from an unknown species; therefore the identification has to be considered individually and carefully in these cases.

It is important to note that the signal strengths given in the plot are not directly related to the concentrations of the species in the breath. For the determination of the concentrations in the volunteers' breath, the concentration factors in the Tenax (C) adsorber have to be determined for each compound which can be done by reference measurements as described in Reference [20]. Furthermore, the signal strengths are directly related to the individual line strengths of each absorption line which are already cataloged for many molecules in data bases such as the JPL molecular spectroscopy data base [24], but not for all species so far. The data bases can be extended by reference measurements and quantum mechanical calculations. At this stage, our measurements allow only for a comparison between the samples from the patients as well as for qualitative statements. This is similar to several studies with other breath sensors as for instance published in [12].

The largest signals in all samples were measured for water and methanol. Comparably high concentrations of water and methanol are expected to be present in ambient, humid air and exhaled breath. However, despite quite some effort, contamination of the vacuum system, in particular from water, cannot be excluded because outgassing water is a general problem in vacuum systems. In all samples, hydrogen cyanide (HCN) was detected with signal strengths within a factor of 2.5 and with the lowest level in ambient air. It was detected with only one absorption line, because it is the only line in the available frequency range. However, the identification is very likely correct, because the measured line is very strong and HCN is a known component of atmospheric air [40]. It is furthermore known to have background levels of around $4 \mathrm{ppb}$ in average in exhaled breath and has been suggested as a diagnostic tool for cyanide poisoning and for cyanide-producing bacterial infections [41]. Carbon monoxide (CO) was as well detected in all samples, but with three to four times higher signals in the volunteers' samples than in the sample of ambient air. CO is a common 
pollutant in indoor and outdoor air having typical concentrations between 0.5 and 5 ppm [42]. Finally, formaldehyde, acetaldehyde, and carbonyl sulfide were detected in all specimens but with higher concentrations in the breath samples. These compounds were also detected in room air and exhaled breath in earlier studies [43]. Some species were detected in samples from all persons but not in ambient air, as for example acetonitrile and acetone. The latter is a breath gas common to all humans [3]. It was, for example, proposed as a biomarker for diabetes in case of very high concentrations [11]. Acetonitrile revealed a 3.5 to 5 times higher level in the smoker's sample (P3). This result is in accordance with earlier studies, reporting higher levels of this component of tobacco smoke [44] in smokers' exhaled breath $[8,18]$. Ethanol is present only in samples P1 and P3 with a 17 times higher level in the latter. Related to that, both persons revealed the highest levels of acetaldehyde (by factors of 2 and 5 compared to P2), which is a product of human ethanol metabolism.

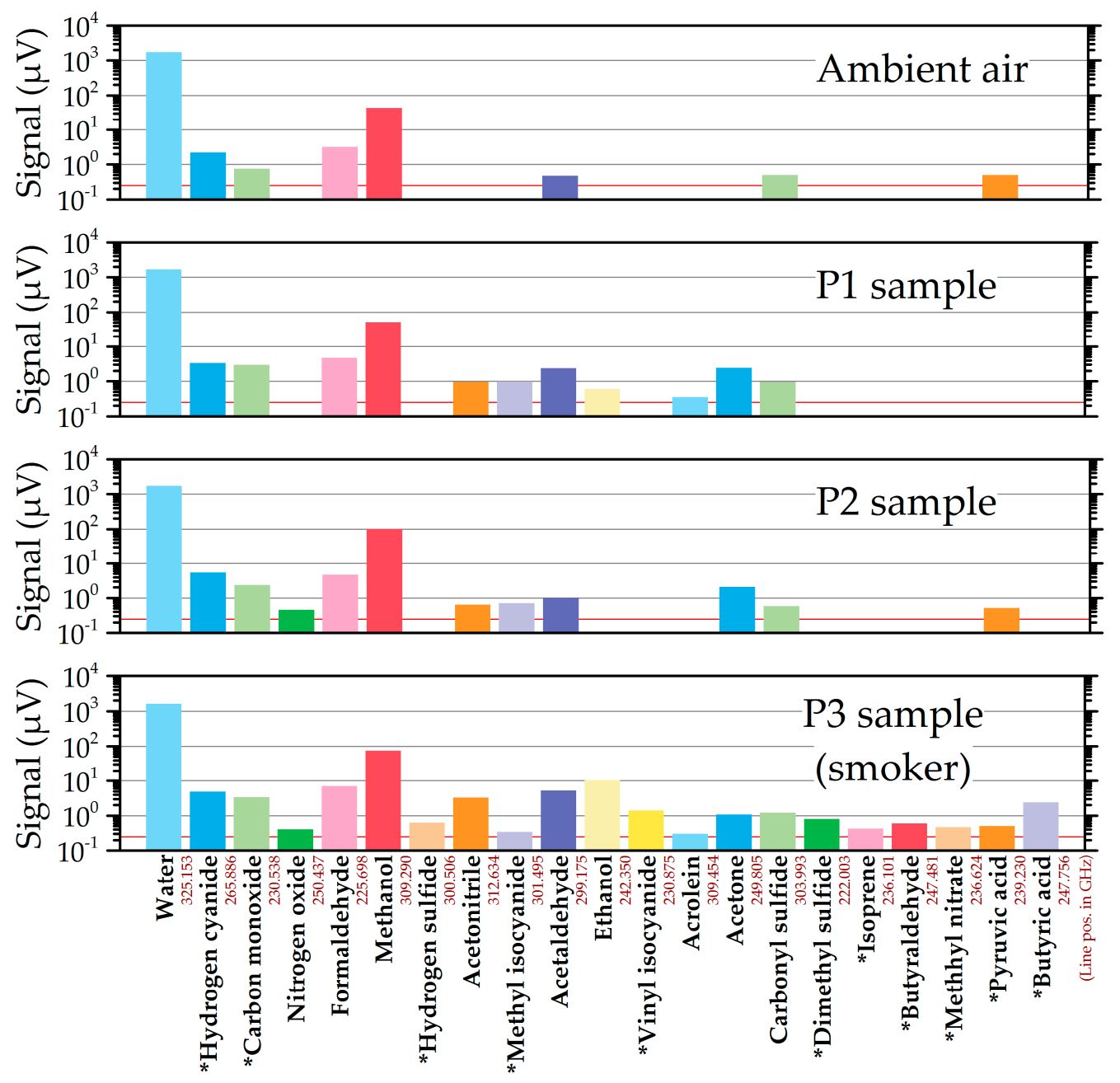

Figure 4. Results of the absorption line scans for ambient air and the three volunteers' samples. For each detected species, the maximum peak-to-peak signal of the stronger absorption line is shown. Molecules, which were detected by only one transition, are marked by a star. The root-mean-square (RMS) noise level of $250 \mathrm{nV}$ is indicated by the red line. The red numbers are the line positions in GHz.

Detections with only one observed absorption line include dimethyl sulfide or methyl nitrate. Dimethyl sulfide is a gas responsible for a pungent odor of the breath and it is linked to liver cirrhosis [45] whereas methyl nitrate was reported to be correlated with the acute, spontaneous hyperglycemia of type 1 diabetes mellitus of children [46]. In both cases, the detected signals were very weak such that the second line was possibly below the detection limit, because it has an even smaller line strength. 
For hydrogen sulfide, the second line at $314.4 \mathrm{GHz}$ was particularly weak (by a factor of 4,000 compared to the first line at $300.5 \mathrm{GHz}$ ). Isoprene was also detected by only one very weak line and only in the sample of the smoker (P3), which is somewhat unexpected, because it is known to be a major constituent of breath for all humans [12,43]. Most likely, the isoprene transitions have very small line strengths. Unfortunately, the data base of isoprene is not complete and the line strengths are not known. Despite the excellent specificity of $\mathrm{mmW} / \mathrm{THz}$ spectroscopy, single line detections have to be interpreted carefully and should be preferably confirmed by additional lines which were not found in our study.

Generally, it can be seen from the data that a large variety of compounds were detected in all samples with signals spanning three orders of magnitude. The volunteers' samples revealed slightly more overall signals than the ambient air sample. In particular, the smoker's sample resulted in the highest signals in most cases. In addition, this sample contained the highest number of compounds including several which were not detected in the other samples.

\section{Conclusions}

We have demonstrated sensitive and specific breath gas analysis by $\mathrm{mmW} / \mathrm{THz}$ gas spectroscopy. This proof of concept approach was aimed to generate the first datasets on breathomics for three healthy volunteers among them one smoking healthy volunteer. Breath samples from the three volunteers along with one sample of ambient air were taken by an established sampling procedure with Tenax@ adsorption tubes. The gas samples were thermally desorbed into a gas cell, where the gas mixture was analyzed with respect to a list of 31 molecular species. The molecules were identified by their $\mathrm{mmW} / \mathrm{THz}$ absorption spectra. Two absorption lines of each compound (in two cases one line) were measured. In total, 21 different species were successfully detected in the samples. Until now the physiological and pathophysiological origins of the substances are not really understood but the sensitivity, specificity, and reproducibility of the measurement method allows for comparison between the samples. In order to increase the sensitivity of the system, future work will involve two measures. First, the sensitivity of the spectrometer will be increased by improving the absorption cell and the optics. Second, the gas extraction from the Tenax@ tube will be improved, for example by purging and by reducing the water content. Furthermore it is desirable to quantify the gases' concentrations in breath down to a level of ppt. For the quantification, reference spectra of some breath-relevant VOCs, as for instance isoprene, have to be measured in the $\mathrm{mmW} / \mathrm{THz}$ frequency range. Including more absorption lines for each species and using versatile data analysis techniques, for example artificial intelligence methods, will improve the results. It has been shown that the analysis of complex mmW/THz molecular spectra benefits from such methods [47]. Another important step for the validation of the results is a systematic comparison with well-established methods such as GC-MS. However, even without the determination of absolute quantities, the results presented in this paper allow for a comparison between the individual samples, similar to previous breath analysis studies [12]. A particularly important development will be focused on the TX and RX. By replacing the current devices with TX and RX fabricated in CMOS or SiGe BiCMOS technology, the cost and complexity of the spectrometer can be drastically reduced, which may open the path towards widely used $\mathrm{mmW} / \mathrm{THz}$ breath analysis.

It has been shown that the gas sensor approach has potential in VOC sampling. We aim to measure larger numbers of patients in well-defined groups in further studies. For medical purposes, the on-site technology and the straight approach of pattern recognition in VOCs is a promising technology.

Author Contributions: Conceptualization, N.R., O.H., R.K., K.S., and H.-W.H.; methodology, N.R., O.H., R.K., K.S., and H.-W.H.; software, N.R.; validation, N.R.; formal analysis, N.R.; investigation, N.R. and O.H.; resources, O.H., R.K., and H.-W.H.; data curation, N.R.; writing-original draft preparation, N.R. and H.-W.H.; writing-review and editing, N.R., O.H., R.K., K.S., and H.-W.H.; visualization, N.R.; supervision, H.-W.H.; project administration, R.K., K.S., and H.-W.H.; funding acquisition, R.K., K.S., and H.-W.H. 
Funding: This research was funded by the Deutsche Forschungsgemeinschaft (DFG, German Research Foundation), SPP 1857-Electromagnetic Sensors for Life Sciences (ESSENCE), grant number 272356870.

Acknowledgments: The authors thank Michael Greiner-Bär for technical support.

Conflicts of Interest: The authors declare no conflict of interests.

\section{References}

1. Phillips, M. Breath tests in medicine. Sci. Am. 1992, 267, 74-79. [CrossRef] [PubMed]

2. Jones, A.W.; Andersson, L. Comparison of ethanol concentrations in venous blood and end-expired breath during a controlled drinking study. Forensic Sci. Int. 2003, 132, 18-25. [CrossRef]

3. Cao, W. Breath Analysis: Potential for Clinical Diagnosis and Exposure Assessment. Clin. Chem. 2006, 52, 800-811. [CrossRef] [PubMed]

4. De Lacy Costello, B.; Amann, A.; Al-Kateb, H.; Flynn, C.; Filipiak, W.; Khalid, T.; Osborne, D.; Ratcliffe, N.M. A review of the volatiles from the healthy human body. J. Breath Res. 2014, 8, 014001. [CrossRef] [PubMed]

5. Phillips, M.; Herrera, J.; Krishnan, S.; Zain, M.; Greenberg, J.; Cataneo, R.N. Variation in volatile organic compounds in the breath of normal humans. J. Chromatogr. B Biomed. Sci. Appl. 1999, 729, 75-88. [CrossRef]

6. Fenske, J.D.; Paulson, S.E. Human Breath Emissions of VOCs. J. Air Waste Manag. Assoc. 1999, 49, 594-598. [CrossRef]

7. Lawal, O.; Ahmed, W.M.; Nijsen, T.M.E.; Goodacre, R.; Fowler, S.J. Exhaled breath analysis: A review of "breath-taking" methods for off-line analysis. Metabolomics 2017, 13, 110. [CrossRef]

8. Pereira, J.; Porto-Figueira, P.; Cavaco, C.; Taunk, K.; Rapole, S.; Dhakne, R.; Nagarajaram, H.; Câmara, J. Breath Analysis as a Potential and Non-Invasive Frontier in Disease Diagnosis: An Overview. Metabolites 2015, 5, 3-55. [CrossRef]

9. Rydosz, A. A negative correlation between blood glucose and acetone measured in healthy and type 1 diabetes mellitus patient breath. J. Diabetes Sci. Technol. 2015, 9, 881-884. [CrossRef]

10. Rydosz, A. Sensors for Enhanced Detection of Acetone as a Potential Tool for Noninvasive Diabetes Monitoring. Sensors 2018, 18, 2298. [CrossRef]

11. Mathew, T.; Pownraj, P.; Abdulla, S.; Pullithadathil, B. Technologies for Clinical Diagnosis Using Expired Human Breath Analysis. Diagnostics 2015, 5, 27-60. [CrossRef] [PubMed]

12. Gaida, A.; Holz, O.; Nell, C.; Schuchardt, S.; Lavae-Mokhtari, B.; Kruse, L.; Boas, U.; Langejuergen, J.; Allers, M.; Zimmermann, S.; et al. A dual center study to compare breath volatile organic compounds from smokers and non-smokers with and without COPD. J. Breath Res. 2016, 10, 026006. [CrossRef] [PubMed]

13. Paardekooper, L.M.; van den Bogaart, G.; Kox, M.; Dingjan, I.; Neerincx, A.H.; Bendix, M.B.; Ter Beest, M.; Harren, F.J.M.; Risby, T.; Pickkers, P.; et al. Ethylene, an early marker of systemic inflammation in humans. Sci. Rep. 2017, 7, 6889. [CrossRef] [PubMed]

14. Rubin, T.; von Haimberger, T.; Helmke, A.; Lock, J.; Stockmann, M.; Heyne, K. Liver Status Assessment by Spectrally and Time Resolved IR Detection of Drug Induced Breath Gas Changes. Photonics 2016, 3, 31. [CrossRef]

15. Erhart, S.; Amann, A.; Haberlandt, E.; Edlinger, G.; Schmid, A.; Filipiak, W.; Schwarz, K.; Mochalski, P.; Rostasy, K.; Karall, D.; et al. 3-Heptanone as a potential new marker for valproic acid therapy. J. Breath Res. 2009, 3, 016004. [CrossRef] [PubMed]

16. King, J.; Kupferthaler, A.; Frauscher, B.; Hackner, H.; Unterkofler, K.; Teschl, G.; Hinterhuber, H.; Amann, A.; Högl, B. Measurement of endogenous acetone and isoprene in exhaled breath during sleep. Physiol. Meas. 2012, 33, 413-428. [CrossRef] [PubMed]

17. Monks, P.S.; Willis, K.A. Breath analysis. Educ. Chem. 2010, 47, 110.

18. Kischkel, S.; Miekisch, W.; Sawacki, A.; Straker, E.M.; Trefz, P.; Amann, A.; Schubert, J.K. Breath biomarkers for lung cancer detection and assessment of smoking related effects-Confounding variables, influence of normalization and statistical algorithms. Clin. Chim. Acta 2010, 411, 1637-1644. [CrossRef]

19. Risby, T.H.; Solga, S.F. Current status of clinical breath analysis. Appl. Phys. B 2006, 85, 421-426. [CrossRef]

20. Rydosz, A.; Maziarz, W.; Pisarkiewicz, T.; de Torres, H.B.; Mueller, J. A Micropreconcentrator Design Using Low Temperature Cofired Ceramics Technology for Acetone Detection Applications. IEEE Sens. J. 2013, 13, 1889-1896. [CrossRef] 
21. Hrubesh, L.W.; Droege, M.W. Pure-rotational spectrometry: A vintage analytical method applied to modern breath analysis. J. Breath Res. 2013, 7, 037105. [CrossRef] [PubMed]

22. Vaks, V.L.; Domracheva, E.G.; Sobakinskaya, E.A.; Chernyaeva, M.B. Exhaled breath analysis: Physical methods, instruments, and medical diagnostics. Phys. Uspekhi 2014, 57, 684. [CrossRef]

23. De Lucia, F.C. The submillimeter: A spectroscopist's view. J. Mol. Spectrosc. 2010, 261, 1-17. [CrossRef]

24. Pickett, H.M.; Poynter, R.L.; Cohen, E.A.; Delitsky, M.L.; Pearson, J.C.; Müller, H.S.P. Submillimeter, millimeter, and microwave spectral line catalog. J. Quant. Spectrosc. Radiat. Transf. 1998, 60, 883-890. [CrossRef]

25. Medvedev, I.R.; Neese, C.F.; Plummer, G.M.; De Lucia, F.C. Submillimeter spectroscopy for chemical analysis with absolute specificity. Opt. Lett. 2010, 35, 1533-1535. [CrossRef] [PubMed]

26. Wang, C.; Perkins, B.; Wang, Z.; Han, R. Molecular Detection for Unconcentrated Gas with ppm Sensitivity Using 220-to-320-GHz Dual-Frequency-Comb Spectrometer in CMOS. IEEE Trans. Biomed. Circuits Syst. 2018, 12, 709-721. [CrossRef] [PubMed]

27. Neese, C.F.; Medvedev, I.R.; Plummer, G.M.; Frank, A.J.; Ball, C.D.; De Lucia, F.C. Compact Submillimeter/Terahertz Gas Sensor with Efficient Gas Collection, Preconcentration, and ppt Sensitivity. IEEE Sens. J. 2012, 12, 2565-2574. [CrossRef]

28. Schmalz, K.; Wang, R.; Debski, W.; Gulan, H.; Borngräber, J.; Neumaier, P.; Hübers, H.-W. 245 GHz SiGe sensor system for gas spectroscopy. Int. J. Microw. Wirel. Technol. 2015, 7, 271-278. [CrossRef]

29. Rothbart, N.; Hübers, H.-W.; Schmalz, K.; Borngräber, J.; Kissinger, D. Towards Breath Gas Analysis Based on Millimeter-Wave Molecular Spectroscopy. Frequenz 2018, 72, 87-92. [CrossRef]

30. Schmalz, K.; Rothbart, N.; Eissa, M.H.; Borngräber, J.; Kissinger, D.; Hübers, H.-W. Transmitters and receivers in SiGe BiCMOS technology for sensitive gas spectroscopy at 222-270 GHz. AIP Adv. 2019, 9, 015213. [CrossRef]

31. Bigourd, D.; Cuisset, A.; Hindle, F.; Matton, S.; Fertein, E.; Bocquet, R.; Mouret, G. Detection and quantification of multiple molecular species in mainstream cigarette smoke by continuous-wave terahertz spectroscopy. Opt. Lett. 2006, 31, 2356-2358. [CrossRef] [PubMed]

32. Bigourd, D.; Cuisset, A.; Hindle, F.; Matton, S.; Bocquet, R.; Mouret, G.; Cazier, F.; Dewaele, D.; Nouali, H. Multiple component analysis of cigarette smoke using $\mathrm{THz}$ spectroscopy, comparison with standard chemical analytical methods. Appl. Phys. B 2007, 86, 579-586. [CrossRef]

33. Hindle, F.; Bray, C.; Hickson, K.; Fontanari, D.; Mouelhi, M.; Cuisset, A.; Mouret, G.; Bocquet, R. Chirped Pulse Spectrometer Operating at 200 GHz. J. Infrared Millim. Terahertz Waves 2018, 39, 105-119. [CrossRef]

34. Rothbart, N.; Schmalz, K.; Borngräber, J.; Kissinger, D.; Hübers, H.-W. Detection of volatile organic compounds in exhaled human breath by millimeter-wave/terahertz spectroscopy. In Proceedings of the 2018 43rd International Conference on Infrared, Millimeter, and Terahertz Waves (IRMMW-THz), Nagoya, Japan, 9-14 September 2018; IEEE: Piscataway, NJ, USA, 2018; pp. 1-2.

35. Fosnight, A.M.; Moran, B.L.; Medvedev, I.R. Chemical analysis of exhaled human breath using a terahertz spectroscopic approach. Appl. Phys. Lett. 2013, 103, 133703. [CrossRef]

36. Medvedev, I.R.; Schueler, R.; Thomas, J.; Kenneth, O.; Nam, H.-J.; Sharma, N.; Zhong, Q.; Lary, D.J.; Raskin, P. Analysis of exhaled human breath via terahertz molecular spectroscopy. In Proceedings of the 2016 41st International Conference on Infrared, Millimeter, and Terahertz waves (IRMMW-THz), Copenhagen, Denmark, 25-30 September 2016; IEEE: Piscataway, NJ, USA, 2016; pp. 1-2.

37. Küppers, L.; Holz, O.; Schuchardt, S.; Gottlieb, J.; Fuge, J.; Greer, M.; Hohlfeld, J.M. Breath volatile organic compounds of lung transplant recipients with and without chronic lung allograft dysfunction. J. Breath Res. 2018, 12, 036023. [CrossRef] [PubMed]

38. Schueler, R. Terahertz Spectroscopic Breath Analysis as a Viable Analytical Chemical Sensing Technique. Ph.D. Thesis, Wright University, Dayton, OH, USA, 2016.

39. Reid, J.; Labrie, D. Second-harmonic detection with tunable diode lasers-Comparison of experiment and theory. Appl. Phys. B 1981, 26, 203-210. [CrossRef]

40. Petrova Simeonova, F.; Fishbein, L. Hydrogen Cyanide and Cyanides: Human Health Aspects; Concise International Chemical Assessment Document; World Health Organization: Geneva, Switzerland, 2004; ISBN 978-92-4-153061-3.

41. Stamyr, K.; Vaittinen, O.; Jaakola, J.; Guss, J.; Metsälä, M.; Johanson, G.; Halonen, L. Background levels of hydrogen cyanide in human breath measured by infrared cavity ring down spectroscopy. Biomarkers 2009, 14, 285-291. [CrossRef] [PubMed] 
42. Ryter, S.W.; Choi, A.M.K. Carbon monoxide in exhaled breath testing and therapeutics. J. Breath Res. 2013, 7, 017111. [CrossRef] [PubMed]

43. Filipiak, W.; Ruzsanyi, V.; Mochalski, P.; Filipiak, A.; Bajtarevic, A.; Ager, C.; Denz, H.; Hilbe, W.; Jamnig, H.; Hackl, M.; et al. Dependence of exhaled breath composition on exogenous factors, smoking habits and exposure to air pollutants. J. Breath Res. 2012, 6, 036008. [CrossRef]

44. Campbell, J.K.; Rhoades, J.W.; Gross, A.L. Acetonitrile as a Constituent of Cigarette Smoke. Nature 1963, 198, 991-992. [CrossRef]

45. Chen, S.; Zieve, L.; Mahadevan, V. Mercaptans and dimethyl sulfide in the breath of patients with cirrhosis of the liver: Effect of feeding methionine. Transl. Res. 1970, 75, 628-635.

46. Novak, B.J.; Blake, D.R.; Meinardi, S.; Rowland, F.S.; Pontello, A.; Cooper, D.M.; Galassetti, P.R. Exhaled methyl nitrate as a noninvasive marker of hyperglycemia in type 1 diabetes. Proc. Natl. Acad. Sci. USA 2007, 104, 15613-15618. [CrossRef] [PubMed]

47. Neumaier, P.F.-X.; Schmalz, K.; Borngräber, J.; Wylde, R.; Hübers, H.-W. Terahertz gas-phase spectroscopy: chemometrics for security and medical applications. Analyst 2015, 140, 213-222. [CrossRef] [PubMed]

(C) 2019 by the authors. Licensee MDPI, Basel, Switzerland. This article is an open access article distributed under the terms and conditions of the Creative Commons Attribution (CC BY) license (http://creativecommons.org/licenses/by/4.0/). 